\title{
Effects of uncoated and citric acid coated cerium oxide nanoparticles, bulk cerium oxide, cerium acetate, and citric acid on tomato plants
}

\author{
Ana Cecilia Barrios ${ }^{\mathrm{a}}$, Cyren M. Rico ${ }^{\mathrm{a}, \mathrm{c}}$, Jesica Trujillo- Reyes ${ }^{\mathrm{a}}$, Illya A. Medina-Velo ${ }^{\mathrm{a}, \mathrm{c}}$, Jose R. \\ Peralta-Videa $^{\mathrm{a}, \mathrm{b}, \mathrm{c}}$, Jorge L. Gardea-Torresdey ${ }^{\mathrm{a}, \mathrm{b}, \mathrm{c}^{*}}$
}

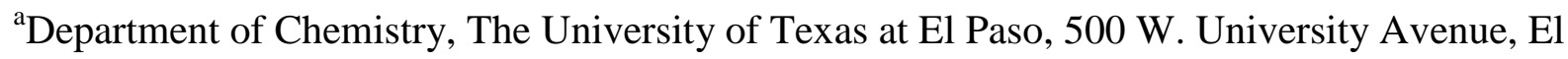
Paso Texas 79968, United States

\author{
${ }^{\mathrm{b}}$ Environmental Science and Engineering Ph.D. Program, The University of Texas at El Paso, \\ 500 W. University Avenue, El Paso Texas 79968, United States \\ ${ }^{c}$ University of California Center for Environmental Implications of Nanotechnology (UC CEIN), \\ The University of Texas at El Paso, 500 West University Ave., El Paso, TX 79968, United States \\ *Corresponding Author: E-mail: jgardea@utep.edu; Phone: 9157475359; fax: 9157475748
}

(C) 2015. This manuscript version is made available under the Elsevier user license http://www.elsevier.com/open-access/userlicense/1.0/ 


\begin{abstract}
Little is known about the physiological and biochemical responses of plants exposed to surface modified nanomaterials. In this study, tomato (Solanum lycopersicum L.) plants were cultivated for 210 days in potting soil amended with uncoated and citric acid coated cerium oxide nanoparticles $\left(\mathrm{nCeO}_{2}, \mathrm{CA}+\mathrm{nCeO}_{2}\right)$ bulk cerium oxide $\left(\mathrm{bCeO}_{2}\right)$, and cerium acetate $(\mathrm{CeAc})$. Millipore water (MPW), and citric acid (CA) were used as controls. Physiological and biochemical parameters were measured. At $500 \mathrm{mg} / \mathrm{kg}$, both the uncoated and $\mathrm{CA}+\mathrm{nCeO}_{2}$ increased shoot length by $\sim 9$ and $\sim 13 \%$, respectively, while $\mathrm{bCeO}_{2}$ and $\mathrm{CeAc}$ decreased shoot length by $\sim 48$ and $\sim 26 \%$, respectively, compared with MPW ( $p \leq 0.05)$. Total chlorophyll, chlo$a$, and chlo- $b$ were significantly increased by $\mathrm{CA}+\mathrm{nCeO}_{2}$ at $250 \mathrm{mg} / \mathrm{kg}$, but reduced by bCeO $\mathrm{Ce}_{2}$ at $62.5 \mathrm{mg} / \mathrm{kg}$, compared with MPW. At 250 and $500 \mathrm{mg} / \mathrm{kg}, \mathrm{nCeO}_{2}$ increased Ce in roots by 10 and 7 times, compared to $\mathrm{CA}+\mathrm{nCeO}_{2}$, but none of the treatments affected the Ce concentration in above ground tissues. Neither $\mathrm{nCeO}_{2}$ nor $\mathrm{CA}+\mathrm{nCeO}_{2}$ affected the homeostasis of nutrient elements in roots, stems, and leaves or catalase and ascorbate peroxidase in leaves. CeAc at 62.5 and $125 \mathrm{mg} / \mathrm{kg}$ increased $\mathrm{B}(81 \%)$ and $\mathrm{Fe}(174 \%)$ in roots, while at 250 and $500 \mathrm{mg} / \mathrm{kg}$, increased $\mathrm{Ca}$ in stems ( $84 \%$ and $86 \%$, respectively). On the other hand, $\mathrm{bCeO}_{2}$ at 62.5 increased $\mathrm{Zn}(152 \%)$ but reduced $\mathrm{P}(80 \%)$ in stems. Only $\mathrm{nCeO}_{2}$ at $62.5 \mathrm{mg} / \mathrm{kg}$ produced higher total number of tomatoes, compared with control and the rest of the treatments. The surface coating reduced Ce uptake by roots but did not affect its translocation to the aboveground organs. In addition, there was no clear effect of surface coating on fruit production. To our knowledge, this is the first study comparing the effects of coated and uncoated $\mathrm{nCeO} 2$ on tomato plants.
\end{abstract}

Keywords: Cerium oxide nanoparticles; surface coating; tomato plant life cycle; fruit production 


\section{Introduction}

Cerium oxide nanoparticles (NPs) or nanoceria $\left(\mathrm{nCeO}_{2}\right)$ are amongst the top 10 nanomaterials produced worldwide (Keller and Lazareva, 2014). Similar to the bulk cerium, these nanoparticles (NPs) are mainly used in the automotive industry as catalysts or in electronics and optics. Keller and Lazareva (2014) estimated that in 2010, the global production $\mathrm{nCeO}_{2}$ reached 10,000 tons of which 100 ended in air, 300 in water and 1,400 in soil. Engineered nanomaterials (ENMs) including $\mathrm{nCeO}_{2}$, have several applications; however, the uncoated forms tend to aggregate and overgrowth, which limit their performance. To improve their stability, ENMs are surface capped with several materials (Niu and Li, 2014). Citric acid (CA) is a common coating agent due to its stability and availability (Masui et al., 2002; Chanteau et al., 2009; Liu et al., 2012). However, coating molecules change the surface chemistry and interaction of ENMs with the environment (Chanteau et al., 2009).

Previous studies have shown that $\mathrm{nCeO}_{2}$ have the potential to alter the physiology and biochemistry of plants. However, there is a lack of uniformity in the reported results and none of the parameters seem to be affected in the same manner when there are variations in species, growth media, and treatment concentration. Lopez-Moreno et al. (2010a) exposed $\mathrm{nCeO}_{2}$ to several seeds in liquid medium and found that at $2000 \mathrm{mg} / \mathrm{L}, \mathrm{nCeO}_{2}$ reduced the germination of tomato (Solanum lycopersicum), corn (Zea mays), and cucumber (Cucumis sativus). LopezMoreno et al. (2010a) also reported an increase in cucumber and corn root seedling elongation but a reduction in alfalfa and tomato root length. On the other hand, Ma et al. (2010) reported that at $2000 \mathrm{mg} / \mathrm{L}, \mathrm{nCeO}_{2}$ reduced the root elongation in lettuce but not in tomato, radish (Raphanus sativus), wheat (Triticum aestivum), cabbage (Brassica oleracea), cucumber, and rape (Brassica napus L.). 
A complete assessment of the effects of $\mathrm{nCeO}_{2}$ on plants is difficult due to the lack of studies covering the entire life cycle. A review of current literature reported that by 2014 , only 30 studies covered the effects of ENMs over the full life cycle of plants (Gardea-Torresdey et al. 2014). Of those, only five were about $\mathrm{nCeO}_{2}$. Wang et al. (2012) exposed tomato in potting soil to consecutive applications of $\mathrm{nCeO}_{2}$ suspension at $10 \mathrm{mg} / \mathrm{L}$. These researchers reported no effects on plant growth and production; however, high Ce content was found in the fruit. Morales et al. (2013) reported that at $250 \mathrm{mg} / \mathrm{kg}, \mathrm{nCeO}_{2}$ decreased biomass and caused conformational changes in the macromolecular composition of cilantro. Rico et al. (2013a, 2014) reported changes in essential elements and other nutritional components in rice (Oryza sativa) and wheat (Triticum aestivum) grains. Zhao et al. (2014) reported 31.3\% reduction in cucumber fruit production under exposure to $800 \mathrm{mg} \mathrm{nCeO} / \mathrm{kg}$; Corral-Diaz et al. (2014) also exposed $\mathrm{nCeO}_{2}$ $(500 \mathrm{mg} / \mathrm{kg})$ to radish and reported no effects in production but changes on the antioxidant power of radish tubers. Rico et al. (2015) reported that $\mathrm{nCeO}_{2}$ increased plant biomass in Hordeum vulgare, but inhibition of grain formation in plants exposed to $500 \mathrm{mg} / \mathrm{kg}$.

Several reports have also shown that $\mathrm{nCeO}_{2}$ affect the activity of stress enzymes. Zhao et al. (2012b) reported that catalase (CAT) and ascorbate peroxidase (APOX) activities increased up to day 15 in shoots of corn seedlings exposed to $\mathrm{nCeO}_{2}$ at $800 \mathrm{mg} / \mathrm{kg}$ soil. Rico et al. (2013b) found a decrease in CAT activity, yet an increase in APOX activity in rice roots exposed to 500 $\mathrm{mg} \mathrm{nCeO} / \mathrm{kg}$ soil. Majumdar et al. (2014) reported a decrease in APOX in kidney bean leaves of plants exposed for 15 days to 250 and $500 \mathrm{mg} \mathrm{nCeO}_{2} / \mathrm{kg}$.

A few studies have shown the effects of surface coating on the interaction of ENMs with plants. Zhao et al. (2012a) reported that the uptake of Ce by corn plants exposed to alginate coated $\mathrm{nCeO}_{2}$ was driven by the soil organic matter. In a more recent study, Trujillo-Reyes et al. 
(2013) found that the Ce uptake by radish was significantly lower in plants exposed to citric acid coated $\mathrm{nCeO}_{2}$, compared to uncoated NPs. Continuous increments in the applications of coated $\mathrm{CeO}_{2}$ NPs increase the chances for their build up in the environment, which could results in unpredicted effects on crop plants. In addition, Hernandez-Viezcas et al. (2013) have shown that $\mathrm{nCeO}_{2}$ taken up by crop plants are stored without changes in plant organs. Tomatoes are berrytype fruits widely consumed in raw form. Thus, they could become a carrier of $\mathrm{nCeO}_{2}$ into the food chain.

In this research, effects of Ce compounds/NPs on the growth, fruit production, uptake of Ce and essential elements, as well as chlorophyll content and the activity of CAT and APOX enzymes were measured in fully developed tomato plants.

\section{Materials and methods}

\subsection{Preparation of nanoparticle suspensions and other treatments}

Uncoated $\mathrm{CeO}_{2} \mathrm{NPs}\left(\mathrm{nCeO}_{2}\right)(10 \mathrm{~nm}$, Meliorum Technologies, Rochester, NY) were obtained from the University of California Center for Environmental Implications of Nanotechnology (UC CEIN). According to a previous characterization (Keller et al., 2010), these $\mathrm{nCeO}_{2}$ have primary size of $8 \pm 1 \mathrm{~nm}$, particle size of $231 \pm 16 \mathrm{~nm}$ in DI water, surface area of $93.8 \mathrm{~m}^{2} \mathrm{~g}^{-1}$, and $95.14 \%$ purity. Citric acid coated $\mathrm{CeO}_{2} \mathrm{NPs}\left(\mathrm{CA}+\mathrm{nCeO}_{2}, 1: 2\right.$ ratio $)$ were prepared and characterized according to Trujillo-Reyes et al. (2013). Enough particles were suspended in an 8:2 v/v water: ethanol solution to reach a $0.001 \mathrm{M}$ concentration. Nanoparticles were sonicated (Crest Ultrasonics, Trenton, NJ) in a water bath for 60 minutes at $20^{\circ} \mathrm{C}$ with a sonication intensity of 180 watts. Another 8:2 v/v water: ethanol solution was prepared with enough citric acid to reach a concentration of $0.002 \mathrm{M}$. The reaction was adjusted to $\mathrm{pH} 7-8$ with a $3 \mathrm{M} \mathrm{NaOH}$ solution. Both solutions were mixed and maintained in reflux for 3 hours. At last, 
ethanol evaporated, and the CNPs were oven dried at $65^{\circ} \mathrm{C}$ for 24 hours. Suspensions/solutions of NPs or compounds including $\mathrm{nCeO}_{2}, \mathrm{CA}+\mathrm{nCeO}_{2}$, bulk $\mathrm{CeO}_{2}\left(\mathrm{bCeO}_{2}\right)$, cerium acetate $(\mathrm{CeAc})$, and citric acid (CA) were prepared with MPW in order to add to each pot $0,62.5,125,250$ and $500 \mathrm{mg} / \mathrm{kg}$ of the respective compound. Each pot was irrigated with $450 \mathrm{ml}$ of the corresponding suspension/solution. These concentrations were selected after Rico et al. (2013b). The calculations were done according to the amount of potting soil used per pot ( 450 g). Suspensions were stirred and sonicated for $30 \mathrm{~min}$ to avoid aggregation before homogeneous mixing with the soil.

\subsection{Seed Germination and plant growth}

Seeds of tomato (Solanum lycopersicum), Roma variety, were purchased from Del Norte Seed \& Feed (Vinton, TX). Seeds were placed in a beaker with MPW and stirred for 3 hours until hydrating. One thousand, six hundred and eighty grams of Miracle-Gro® organic potting mix were separated, put in a glass container, and mixed with the Ce treatments. A brief description of the Miracle-Gro® is shown in Table S9 of the supplementary data. Four hundred and twenty grams of the Ce amended soil and control soil were placed in each pot, creating four replicates per treatment, except the MPW control that had 16 replicates, four for each Ce compound/NP. The soil was left for 24 hours for conditioning before planting.

For germination, seeds of approximately the same size and aspect were selected. Five seeds per replicate/treatment were used. The seeds were placed about $2.5 \mathrm{~cm}$ deep in the soil and watered with $100 \mathrm{~mL}$ of MPW every day. Pots were placed in a greenhouse with 14-h photoperiod, $25 / 20^{\circ} \mathrm{C}$ day/night temperature, $70 \%$ relative humidity under light intensity of 340 $\mu \mathrm{mol} \mathrm{m} \mathrm{m}^{-2}$. The seed germination began on the third day and the stem length was recorded at 15, 30, 60, 120, and 210 days after germination (DAG). At 60 days, four seedlings were removed 
and only the biggest plant in each pot was cultivated to full maturity. The number of fruits per plant and the percent of mature fruits from day 139 to 210 after germination were also recorded.

\subsection{Quantification of Ce, nutrients, and Al in dry plant tissues}

At harvest (210 days), roots, stems and leaves were washed with a $5 \% \mathrm{CaCl}_{2}$ solution and rinsed three times with MPW. Samples were dried for 72 hours in an oven at $60^{\circ} \mathrm{C}$, and grinded with mortar and pestle until powdered. Samples of $0.2 \mathrm{~g}$ of tissues were microwave acid-digested by adding $1 \mathrm{~mL}$ of plasma pure $\mathrm{HNO}_{3}$ and $4 \mathrm{~mL}$ of $30 \%$ hydrogen peroxide in a microwave oven (MarsX, CEM Corporation Mathews, NC). The digests were diluted to $50 \mathrm{~mL}$ with MPW. Micro and macro nutrients, aluminum, and cerium quantification in the acidic solutions was performed using inductively coupled plasma-optical emission spectroscopy (ICP-OES, Perkin Elmer Optima 4300 DV, Shelton, CT). Blanks, spikes and standard reference materials NIST 1547 and peach leaves, (Gaithersburg, MD) were used to validate the digestion and analytical methods for $\mathrm{Ce}, \mathrm{Al}, \mathrm{B}, \mathrm{Ca}, \mathrm{Cu}, \mathrm{Fe}, \mathrm{K}, \mathrm{Mg}, \mathrm{Mn}, \mathrm{P}$ and $\mathrm{Zn}$. For QA/QC, ICP readings of a blank and a standard were done every 15 samples.

\subsection{Catalase (CAT) and ascorbate peroxidase (APOX) assays}

A previous study showed differential effects of the $\mathrm{nCeO}_{2}$ concentrations on different stress enzymes in rice plants (Rico et al. 2013b). In this study we determined the activity of catalase (EC 1.11.1.6) and ascorbate peroxidase (EC 1.11.1.11) in leaves of 210-day old tomato plants grown in potting soil amended with the different Ce-based compounds/NPs. Fresh leaves were washed with a $5 \% \mathrm{CaCl}_{2}$ solution and MPW three times to remove external contaminants. For each sample, $0.2 \mathrm{~g}$ of fresh leaves were grinded in a mortar and pestle and extracted with $1800 \mu \mathrm{L}$ of a phosphate buffer solution $\left(25 \mathrm{mM} \mathrm{KH}_{2} \mathrm{PO}_{4}\right.$ at $\mathrm{pH}$ 7.4). Extracts were centrifuged for $10 \mathrm{~min}$ at $-4^{\circ} \mathrm{C}$ and 9,600 $\mathrm{rpm}$ (Eppendorf AG bench centrifuge $5417 \mathrm{R}$, Hamburg, 
Germany). The supernatants were then transferred to $2 \mathrm{~mL}$ Eppendorf tubes to continue with the assay. Catalase (CAT) activity was done according to Gallego et al. (1996). A $950 \mu \mathrm{L}$ aliquot of $10 \mathrm{mM} \mathrm{H}_{2} \mathrm{O}_{2}$ was placed in a quartz cuvette, and an aliquot of $50 \mu \mathrm{L}$ of the sample was added to obtain a final volume of $1 \mathrm{~mL}$. The mixture was shaken three times by hand, and the absorbance at $240 \mathrm{~nm}$ was recorded for three min in a Perkin Elmer Lambda 14 UV/Vis Spectrometer (single-beam mode, Perkin-Elmer, Uberlinger, Germany). The amount of protein for CAT/APOX was determined by the fresh weight of the tissue employed.

The APOX activity was evaluated according to Murguia et al. (2004). Extract of fresh tomato leaves were prepared as described previously Rico et al. (2013b). The supernatant was separated by centrifugation. An aliquot of $4 \mu \mathrm{L}$ of $25 \mathrm{mM}$ ascorbate, $10 \mu \mathrm{L}$ of $17 \mathrm{mM} \mathrm{H}_{2} \mathrm{O}_{2}, 886$ $\mu \mathrm{L}$ of $0.1 \mathrm{M} \mathrm{KH}_{2} \mathrm{PO}_{4}$ buffered at $\mathrm{pH} 7.4$ and $100 \mu \mathrm{L}$ of fresh leaf extract were placed in a quartz cuvette and mixed three times. The absorbance was recorded at $265 \mathrm{~nm}$ for $2 \mathrm{~min}$ in a Perkin Elmer Lamda 14 UV/Vis Spectrometer. The absorbance was recorded as described above.

\subsection{Chlorophyll content}

Total chlorophyll, chlorophyll $a$ and $b$ (chlo- $a$ and chlo- $b$ ) contents were determined as per Porra et al. (2002). Fresh tomato leaf tissue was cryogenized with liquid nitrogen, and later employed for extractions. A sample of $0.5 \mathrm{~g}$ of leaf tissue was grinded with $80 \%$ acetone for chlorophyll extraction. The extracts were kept in a freezer at $-80^{\circ} \mathrm{C}$ until the assay was performed. The absorbance at 663 and $646 \mathrm{~nm}$ was measured using a Perkin Elmer Lamda 14 UV/Vis Spectrometer.

\subsection{Statistical Analysis}

Four replicates of each treatment concentration were allocated in a completely random design in the greenhouse facility. Data was analyzed using one-way ANOVA (PASW Statistics 
18 software) and the Tukey's HSD test at $p \leq 0.05$ was used to determine statistical differences between treatment means. Data presented are mean \pm standard errors (SE) of four replicates.

\section{Results and Discussions}

\subsection{Cerium concentration in tissues}

Figure 1 shows the cerium concentration in roots, stems and leaves of 210-day old tomato plants grown in soil amended with uncoated and coated $\mathrm{nCeO}_{2}, \mathrm{bCeO}_{2}$, and cerium acetate at 0 to $500 \mathrm{mg} / \mathrm{kg}$. In this study, no Ce was detected in plants exposed to citric acid. As seen in Figure 1 , some treatments affected the Ce accumulation in vegetative organs, compared to their respective MPW control. In roots, there was a concentration-dependent increase of Ce that was statistically higher in plants exposed to $\mathrm{nCeO}_{2}$ at 125,250 and $500 \mathrm{mg} / \mathrm{kg}(\sim 41 \pm 8.1,130 \pm 18.0$ and $197 \pm 20 \mathrm{mg} / \mathrm{kg} \mathrm{d} \mathrm{wt,} \mathrm{respectively),} \mathrm{compared} \mathrm{to} \mathrm{control.} \mathrm{Moreover,} \mathrm{root} \mathrm{Ce} \mathrm{at} 250$ and 500 $\mathrm{mg} / \mathrm{kg}$ of $\mathrm{nCeO}_{2}$ was statistically higher, compared to 62.5 and $125 \mathrm{mg} / \mathrm{kg}$. At all concentrations $\mathrm{CA}+\mathrm{nCeO}_{2}, \mathrm{bCeO}_{2}$ and $\mathrm{CeAc}$ significantly increased $\mathrm{Ce}$ concentration in roots, compared with their respective controls (Figure 1A). The data suggests that the concentration of Ce in roots was not associated with the solubility of the compounds. The solubility of $\mathrm{nCeO}_{2}$ is $1.28 \mathrm{~g} / \mathrm{L}$ (Dahle and Arai, 2015) and the solubility of CeAc is $3.5 \mathrm{~g} / \mathrm{L}$

(http://www.gelest.com/goods/pdf/metalOrganicCatalog/58.pdf). The difference could be due to a high absorption of uncoated NPs plus particles adsorbed to the root surface that were not removed by the washing process. The surface coating significantly reduced the Ce uptake by roots (Fig 1A). The Ce concentration in roots of plants exposed to coated NPs was seven times lower than in plants exposed to uncoated NPs (Table S5). This could be a result of the different interactions of coated and uncoated NPs with the root surface, due to the $\zeta$ potential of the particles. Uncoated $\mathrm{nCeO}_{2}$ had a $\zeta$ potential of $20.1 \pm 1.2 \mathrm{mV}$ and the $\zeta$ potential of coated 
$\mathrm{nCeO}_{2}$ was $-57 \pm 0.6 \mathrm{mV}$ (Trujillo-Reyes et al. 2014). Thus, the negative surface charge of the root plasma membrane (Wang et al. 2014) repelled the negatively charged coated NPs. TrujilloReyes et al. (2014) found similar results in radish exposed to citric acid coated $\mathrm{nCeO}_{2}$. Similar results were also reported by Zhao et al. (2012a) in corn roots exposed to alginate coated $\mathrm{nCeO}_{2}$.

Previous studies have shown that $\mathrm{nCeO}_{2}$ tend to remain in roots (Wang et al. 2012; Zhao et al. 2012a; Schawbe et al. 2013; Chichiricco and Pomma, 2015). Zhao et al. (2012a) reported that the translocation of $\mathrm{Ce}$ in corn plants exposed to alginate coated $\mathrm{nCeO}_{2}$ was driven by the soil organic matter. These authors found that shoots of plants grown in low organic matter soil amended with 200 and $400 \mathrm{mg} / \mathrm{kg}$ of alginate coated $\mathrm{nCeO}_{2}$ "had 104 and 106\%, respectively, more Ce compared with plants grown in organic soil." Trujillo-Reyes et al. (2014) exposed uncoated and citric acid coated $\mathrm{nCeO}_{2}$ to radish seedlings in hydroponics. Authors did not report translocation as they measured the whole seedling; however, they found $94 \%$ less Ce in plants exposed to coated NPs. In our study, none of the treatments showed high Ce translocation to the above ground tissues. In stems, Ce concentrations were, in general, $<0.8 \mathrm{mg} / \mathrm{kg} \mathrm{d}$ wt, while in leaves were $\leq 2 \mathrm{mg} / \mathrm{kg} \mathrm{d}$ wt (Table S5) In stems, only the $\mathrm{nCeO}_{2}$ at 125 and $500 \mathrm{mg} / \mathrm{kg}(\sim 0.67 \pm$ 0.03 and $0.61 \pm 0.07 \mathrm{mg} / \mathrm{kg} \mathrm{d} \mathrm{wt}$, respectively) showed a statistical difference with respect to the MPW control $(\sim 0.36 \pm 0.07 \mathrm{mg} / \mathrm{kg} \mathrm{d} \mathrm{wt})$. Uncoated $\mathrm{nCeO}_{2}$ also increased at $62.5 \mathrm{mg} / \mathrm{kg}$ in tomato leaves when compared to the control $(2.1 \pm 0.7$ and $0.9 \pm 0.2 \mathrm{mg} / \mathrm{kg}$, respectively) (Figures 1B-C). In addition, none of the treatments showed Ce accumulation in fruit. This result differs from the result reported by Wang et al. (2012) who reported "substantially higher Ce concentrations" in fruit of plants that were fed with $130 \mathrm{mg}$ of $\mathrm{CeO}_{2} / \mathrm{kg}$ of dry potting mix during the entire life cycle. Perhaps the difference was due to the exposure methodology. In our study, the whole amount of NPs was applied to the soil 24 hours before seeding, while Wang et al. fed 
the plants twice a week until harvesting with a NP suspension at $10 \mathrm{mg} / \mathrm{L}$. In addition, the Miracle-Gro potting mix has a high content of organic matter (50-60 percent forest products, as shown in Table S9), which has been shown to bind NPs (Grillo et al. 2015)

\subsection{Chlorophyll content in leaves}

Figure 2 shows total chlorophyll, chlo- $a$, and chlo- $b$ in leaves of tomato plants cultivated in soil amended with $\mathrm{nCeO}_{2}, \mathrm{CA}+\mathrm{nCeO}_{2}, \mathrm{bCeO}_{2}, \mathrm{CeAc}$ and citric acid (Table S6). As seen in Figure 2 (A-C) only the $\mathrm{bCeO}_{2}$ at $62.5,250$ and $500 \mathrm{mg} / \mathrm{kg}$ affected the chlorophyll production. At $62.5 \mathrm{mg} / \mathrm{kg}$ the $\mathrm{bCeO}_{2}$ treatment significantly reduced total chlorophyll and chlo- $a$, compared with control, 250 and $500 \mathrm{mg} / \mathrm{kg}$. This suggests less production of ATP that can affect the general performance of the plants (Rabinowitch and Govindjee, 1965). However, at 250 and 500 $\mathrm{mg} / \mathrm{kg}$ from $\mathrm{bCeO} 2$ increased total chlorophyll and chlo- $a$ with respect to the MPW control. Our results concur with previous reported results with $\mathrm{nCeO}_{2}$. Zhao et al. $(2014,2015)$ reported that $\mathrm{nCeO}_{2}$ did not alter leaf net photosynthetic rate, gas exchange, stomata conductance, transpiration rate and total chlorophyll content in cucumber and corn. These results contrast with previous studies which note that nanoparticles procure a negative effect on the chlorophyll content (Perreault et al., 2010; Rico et al., 2013b; Mohammed et al., 2011; Mazumdar et al., 2014). This corroborate that the response to NPs varies with several factors, including the growth medium, the environment, and plant species. In the present study, the surface modification of $\mathrm{nCeO}_{2}$ did not change the impact on chlorophyll production.

\subsection{Catalase and Ascorbate peroxidase activities}

The defense mechanism of plants is sometimes activated by environmental, biological, or chemical stress. Catalase and ascorbate peroxidase are enzymes that deal with stress by fighting 
the reactive oxygen species (ROS) generated by the plants in the form of $\mathrm{H}_{2} \mathrm{O}_{2}$ (Panda, 2005). Figure 3 (A-B) shows the activity of CAT and APOX in leaves of 210-day old tomato plants. As seen in this figure, none of the concentrations of $\mathrm{nCeO}_{2}$ significantly affected CAT activity, compared with control; while coated NPs at $500 \mathrm{mg} / \mathrm{kg}$, significantly increased CAT, compared with control. It is possible that at concentrations $<500 \mathrm{mg} / \mathrm{kg}$, the plant could cope with the stress imposed by the $\mathrm{CA}+\mathrm{nCeO}_{2}$. On the other hand, the activity of APOX showed the same reduction pattern under exposure to both uncoated and coated NPs, except at $62.5 \mathrm{mg} / \mathrm{kg}$, where coated NPs did not affect APOX activity. Differences in CAT activity on plants exposed to uncoated and coated NPs suggest that the coating reduced the CAT mimetic activity $\mathrm{nCeO}_{2}$ (Pirmohamed et al., 2010). However, it seems that the coating does not reduce the peroxidaselike activity of $\mathrm{nCeO}_{2}$, as APOX activity in tomato showed, in general, the same pattern.

Catalase activity was significantly reduced by $\mathrm{bCeO}_{2}$ at $125 \mathrm{mg} / \mathrm{kg}$, but surprisingly, increased at 250 and $500 \mathrm{mg} / \mathrm{kg}$, although the difference at $500 \mathrm{~g} / \mathrm{kg}$ did not reach statistical significance, compared with control. Similarly, at $125 \mathrm{mg} / \mathrm{kg}$, CeAc significantly increased CAT activity, compared with control (Figure 3A). The effects of bCe and CeAc were different on APOX activity. While practically all $\mathrm{bCeO}_{2}$ concentrations significantly reduced the activity, only the highest concentrations of CeAc (250 and $500 \mathrm{mg} / \mathrm{kg})$ significantly reduced APOX activity, compared with control. In CeAc, cerium is in the trivalent state (Ce(III)), which easily binds to phosphates and hydroxides and has lower catalase mimetic activity (Pirmohamed et al., 2010), while in $\mathrm{bCeO}_{2}$ it exist as both $\mathrm{Ce}(\mathrm{III}) / \mathrm{Ce}(\mathrm{IV})$ that has shown to have superoxide dismutase and peroxidase scavenging activity (Rico et al., 2015). This can explain the effects of both compounds on CAT and peroxidase activities. 
None of the citric acid concentrations modified CAT activity, and only at $250 \mathrm{mg} / \mathrm{kg}$, there was a significant reduction in APOX activity, compared with control (Figure 3B). However, the difference was not clear as the average obtained at $250 \mathrm{mg} / \mathrm{kg}$, overlap with the averages observed at other concentrations, and these overlapped with control. Previous reports have shown different effects of $\mathrm{nCeO}_{2}$ on plants. Further comparisons between the treatments can be observed in the Table S7.Morales et al. (2013) did not report changes on CAT activity in cilantro exposed to 0 to $500 \mathrm{mg} / \mathrm{kg}$ in similar soil to the one used in this study. Zhao et al. (2012b) cultivated corn in soil amended with 400 and $800 \mathrm{mg} \mathrm{nCeO} / \mathrm{kg}$. These researchers reported an increase in $\mathrm{H}_{2} \mathrm{O}_{2}$, concomitant with increases in CAT and APOX, but only in 10-day old plants, suggesting that corn rapidly generated an adaptive response to the stress imposed by the NPs.

\subsection{Nutrient element accumulation}

Previous studies have shown that ENMs alter the uptake and translocation of nutrient elements. In the present study, all macro and microelements were analyzed in root, stem, leaf, and fruit (Table 1 and Supplementary data Tables S1-S3). However, only Al (a non-essential element), B, Ca, Fe, P and Zn showed statistically significantly differences, compared with control (Table 1). As seen in this table, CeAc at 62.5 and $125 \mathrm{mg} / \mathrm{kg}$ increased B (81\%) and Fe $(174 \%)$ in roots, while at 250 and $500 \mathrm{mg} / \mathrm{kg}$, increased $\mathrm{Ca}$ in stems $(84 \%$ and $86 \%$, respectively). On the other hand, $\mathrm{bCeO}_{2}$ at 62.5 increased $\mathrm{Zn}(152 \%)$ but reduced $\mathrm{P}(80 \%)$ in stems. Coated $\mathrm{nCeO}_{2}$ increased $\mathrm{Al}$ in roots (175\%) and leaves (180\%). CeAc has a Ksp of 0.35 $\mathrm{g} / 100 \mathrm{~g} \mathrm{H}_{2} \mathrm{O}$; this means that the acetate ion may function as a chelating agent for cations, increasing their absorption. It is not clear how the coated NPs increased Al absorption; however, in a previous study Trujillo-Reyes et al. (2013) found that citric acid coated $\mathrm{nCeO}_{2}$ increased $\mathrm{Al}$ 
uptake by $93 \%$ in radish. Perhaps the negative surface charge of the coated NPs bound Al, facilitating its uptake. More studies are needed in order to elucidate these results.

\subsection{Stem growth}

Table 3 shows the stem length of tomato plants at 15, 60, and 210 days after germination. As one can observe in this table, both the uncoated and coated NPs affected the growth at 60 days after germination. At this stage, uncoated NPs at 62.5 and 125 and coated at $62.5 \mathrm{mg} / \mathrm{kg}$ reduced stem growth, compared with control. Mixed results were observed at 210 days; however, at $500 \mathrm{mg} / \mathrm{kg}$ uncoated and coated NPs increased stem length by 9 and 13\%, respectively, compared with MPW control. The current data is not enough to explain the effects on stem elongation as, practically, the NPs did not affect chlorophyll contents and nutrient uptake. A previous study showed that $\mathrm{nCeO}_{2}$ reduced radish root biomass and stem length, while citric acid coated $\mathrm{nCeO}_{2}$ increased root biomass (Trujillo-Reyes et al. 2013). The results observed with coated NPs in tomato do not seem to be driven by the external citric acid that could be released by the coated NPs. Mudunkotuwa and Grassian (2010) have shown that at the pH used in this study, citric acid is fully deprotonated and tightly bound to NPs. Then, it could be due to surface modifications that interfered with other functions of the plants not analyzed in this study.

Citric acid showed no significant effect at 15 days but mixed results at 60 days, while concentrations of 250 and $500 \mathrm{mg} / \mathrm{kg}$ produced significant reduction in stem elongation at 120 days, but the plants recovered at 210 days (Table S8). Citric acid is normally synthesized by tomato plants and can protect the plants by chelating excess of elements (Table S4), or it can help the plant to uptake some elements found at low concentrations in the soil solution (Senden et al., 1995). In this study, citric acid did not increase elements in tissues, neither affect chlorophyll nor CAT and APOX. Thus, this should be the reason why at the end of the cycle, 
plants were not affected. Bulk cerium also showed mixed results at 30 days. However, at 120 and 210 days, all concentrations showed a consistent and significant stem reduction, compared with control and the other treatments. At 210 days, $\mathrm{bCeO}_{2}$ and $\mathrm{CeAc}$ decreased shoot length by 48 and $\sim 26 \%$, respectively, compared with MPW $(\mathrm{p} \leq 0.05)$. Our data concurs with the data reported by Majumdar et al. (2014) who found that in red kidney bean there was a decrease in stem biomass in plants exposed to $\mathrm{bCeO}_{2}$, compared to $\mathrm{nCeO}_{2}$. Majumdar et al. (2014) also reported a correlation among the stress and the reduction in biomass. In tomato, $\mathrm{bCeO}_{2}$ at 250 and $500 \mathrm{mg} / \mathrm{kg}$ significantly increased CAT but reduced APOX, which could be the reason for the stem growth reduction. Cerium acetate also reduced stem length in adult plants exposed to 250 and $500 \mathrm{mg} / \mathrm{kg}$. Cerium acetate $\left(\mathrm{Ce}^{3+}\right)$, has shown to have superoxide scavenging activity but not catalase activity (Pirmohamed et al., 2010). Due to that, in general, CeAc did not affect CAT activity, but reduced APOX activity at 250 and $500 \mathrm{mg} / \mathrm{kg}$. This reduction on APOX activity prevents the reduction of $\mathrm{H}_{2} \mathrm{O}_{2}$ generated by SOD into $\mathrm{H}_{2} \mathrm{O}$ (Rico et al., 2015). Excess of $\mathrm{H}_{2} \mathrm{O}_{2}$, one of the reactive oxygen species, is translated in toxicity, which in turn reduced the growth of stems.

\subsection{Fruit production}

Table 2 shows the absolute number of ripe fruits collected from the tomato plants exposed to the different treatments. Although the greenhouse had good conditions for the plant to grow, the light intensity $\left(340 \mu \mathrm{mol} \mathrm{m} \mathrm{s}^{-2}\right)$ was not high enough to support good fruit production as tomatoes grow better under full light exposure. Thus, this table shows the total number of fruits, but the data was not representative for a statistical analysis. The data gathered showed that most of control plants got mature fruits in normal period (http://tchester.org/analysis/tomatoes/). The percent of ripe tomatoes in MPW control treatments 
at 151 days varied from $57 \%$ (controls for coated NPs) to $100 \%$ (controls for CeAc treatments). Interestingly, all uncoated and coated NP treatments, except $500 \mathrm{mg} / \mathrm{kg}$, had ripe tomatoes at 151 days. However, plants exposed $\mathrm{bCeO}_{2}$ at 62.5 did not produced ripe tomatoes at 151 days, plants exposed to $125 \mathrm{mg} / \mathrm{kg}$ did not produce any tomatoes, while plants exposed to 250 and $500 \mathrm{mg} / \mathrm{kg}$ had $50 \%$ and $40 \%$ ripe tomatoes, respectively, at 151 days. It is worth noting that plants exposed to coated NPs, except at $125 \mathrm{mg} / \mathrm{kg}$, had blossom end rot. This is a serious tomato disorder associated with $\mathrm{Ca}$ deficiency that can affect more than $50 \%$ of production (http://ohioline.osu.edu/hyg-fact/3000/pdf/3117.pdf). However, none of the NPs interfered with Ca accumulation in fruit (data not shown); in addition, there was a regular water supply, and the pH was around 6.5 (Table S9). This suggests that other factors were involved in the induction of the blossom end rot, which deserves additional investigation.

\section{Conclusions}

The data of this study suggests that tomato stem elongation, in fully developed plants, was enhanced at the highest concentration of both coated and uncoated nanoparticle treatments, but was reduced by $\mathrm{bCeO}_{2}$ and $\mathrm{CeAc}$ compounds at 210 days after germination. The citric acid coating did not have effect on chlorophyll $a, b$ and total chlorophyll contents of tomato.

However, the surface coating had effect on the biochemical response of the plant as coated NPs increased CAT activity at $500 \mathrm{mg} / \mathrm{kg}$. On the other hand, at $125 \mathrm{mg} / \mathrm{kg}, \mathrm{bCeO}_{2}$ decreased CAT activity by $83.90 \%$. Both coated and uncoated NPs showed similar reducing effects on APOX, except at $62.5 \mathrm{mg} / \mathrm{kg}$, where coated NPs did not affect APOX. In addition, all $\mathrm{bCeO}_{2}$ concentrations and CeAC at 250 and $500 \mathrm{mg} / \mathrm{kg}$ reduced APOX activity. ICP-OES results demonstrated that the coating reduced Ce uptake by roots but did not have effect on its translocation to the aboveground plant parts. Neither uncoated nor coated $\mathrm{nCeO}_{2}$ affected the 
homeostasis of nutrient elements in roots, stems, and leaves, and there was no clear effect of surface coating on the fruit production of tomato plants. To our knowledge, this is the first life cycle study comparing the effects of coated and uncoated $\mathrm{nCeO}_{2}$ on tomato plants.

\section{Acknowledgements}

This material is based upon work supported by the National Science Foundation and the Environmental Protection Agency under Cooperative Agreement Number DBI-0830117. Any opinions, findings, and conclusions or recommendations expressed in this material are those of the author(s) and do not necessarily reflect the views of the National Science Foundation or the Environmental Protection Agency. This work has not been subjected to EPA review and no official endorsement should be inferred. This work was also supported by Grant 2G12MD007592 from the National Institutes on Minority Health and Health Disparities (NIMHD), a component of the National Institutes of Health (NIH). Authors also acknowledge the USDA grant 2011-38422-30835 and the NSF Grants EEC-1449500, CHE-0840525 and DBI1429708. J. L. Gardea-Torresdey acknowledges the Dudley family for the Endowed Research Professorship, the Academy of Applied Science/US Army Research Office, Research and Engineering Apprenticeship program (REAP) at UTEP, grant \# W11NF-10-2-0076, sub-grant 13-7, and STARs programs of the University of Texas System. A. C. Barrios acknowledges the Louis Stokes Alliance for Minority Participation (LSAMP) Bridge to the Doctorate FellowshipNSF grant HRD-1202008.

\section{References}

Chanteau, B., Frsnais, J., Berret, J.-F. 2009. Electrosteric enhanced stability of functional sub-10 $\mathrm{nm}$ cerium and iron oxide particles in cell culture medium. Langmuir 25(16), 90649070 .

Chichiricco, G., Poma, A. 2015. Penetration and toxicity of nanomaterials in higher plants. 
Nanomaterials 5, 851-873.

Corral-Diaz, B., Peralta-Videa, J.R., Alvarez-Parrilla, E., Rodrigo-Garcia, J., Morales, M.I., Osuna-Avila, P., Niu, G., Hernandez-Viezcas, J.A., Gardea-Toresdey, J.L. 2014. Cerium oxide nanoparticles alter the antioxidant capacity but do not impact tuber ionome in Raphanus sativus (L). Plant Physiol. Biochem. 84, 277-285.

Dahle, J.T., Arai, Y. 2014. Environmental geochemistry of cerium: applications and toxicology of cerium oxide nanoparticles. Int. J. Environ. Res. Public Health 12, 1253-1278.

Gallego, S.M., Benavides, M. P., Tomaro, M.L. 1996. Effect of heavy metal ion excess on sunflower leaves: evidence for involvement of oxidative stress. Plant Sci. 121, 151-159.

Gardea-Torresdey, J.L., Rico, C.M., White, J.C. 2014. Trophic transfer, transformation, and impact of engineered nanomaterials in terrestrial environments. Environ. Sci. Technol. 48, 2526-2540.

Grillo, R., Rosa, A.H., Fraceto, L.F. 2015. Engineered nanoparticles and organic matter: A review of the state of the art. Chemosphere 119, 608-619.

Hernandez-Viezcas, J.A., Castillo-Michel, H., Andrews, J.C., Cotte, M., Rico, C.M., PeraltaVidea, J.R., Priester, J.H., Holden, P.A., Gardea-Torresdey, J.L. 2013. In situ synchrotron fluorescence mapping and coordination of $\mathrm{CeO}_{2}$ and $\mathrm{ZnO}$ nanoparticles in soil cultivated soybean (Glycine max). ACS Nano 7 (2), 1415-1423.

Keller, A.A., Lazareva, 2014. Predicted releases of engineered nanomaterials: from global to regional to local. Environ. Sci. Technol. Lett. 1(1), 65-70.

Keller, A.A., Wang, H., Zhou, D., Lenihan, H.S., Cherr, G., Cardinale, B.J., Miller, R., Ji, Z., 2010. Stability and aggregation of metal oxide nanoparticles in natural aqueous matrices. Environ. Sci. Technol. 44 (6), 1962-1967.

Liu, J., Legros, S., Ma, G., Veinot, J.G.C., von der Kammer, F., Hofmann, T. 2012. Influence of Surface functionalization and particle size on the aggregation kinetics of engineered nanoparticles. Chemosphere 87, 918-924.

Lopez-Moreno, M. L., De la Rosa, G., Hernandez-Viezcas, J. A., Peralta-Videa, J. R., GardeaTorresdey, J. L. 2010a. X-ray absorption spectroscopy (XAS) corroboration of the uptake and storage of $\mathrm{CeO}_{2}$ nanoparticles and assessment of their differential toxicity in four edible plant species. J. Agric. Food Chem. 58, 3689-3693.

Ma, Y., Kuang, L., He, X., Bai, W. Ding, Y., Zhang, Z., Zhao, Y., \& Chai, Z. 2010. Effects of rare earth oxide nanoparticles on root elongation of plants. Chemosphere 78(3), 273279.

Majumdar S., Peralta-Videa J.R., Bandyopadhyay, S., Castillo-Michel, H., Hernandez-Viezcas, J.A., Sahi, S., Gardea-Torresdey, J.L. 2014. Exposure of cerium oxide nanoparticles to kidney bean shows disturbance in the plant defense mechanisms, J. Hazard. Mater. 278, 279-287. 
Masui, T., Hirai, H., Imanaka, N., Adachi, G., Sakata, T., Mori, H. 2002. Synthesis of cerium oxide nanoparticles by hydrothermal crystallization with citric acid. J. Mater. Sci. Lett. $21,489-491$.

Mazumdar, H. 2014. The impact of silver nanoparticles on plant biomass and chlorophyll content. Research inventy: Int. J. Eng. Sci. 4 (7), 12-20.

Mohammed Sadiq, I. M.; Pakrashi, S.; Chandrasekara, N.; Mukherjee, A. 2011. Studies on toxicity of aluminum oxide (A12O3) nanoparticles to microalgae species: Scenedesmus sp. and Chlorella sp. J. Nanopart. Res. 13, 3287-3299.

Morales, M.I., Rico, C.M., Hernandez-Viezcas, J.A., Nunez, J.E., Barrios A.C., Tafoya, A., Flores-Marges, J.P., Peralta-Videa, J. R., Gardea-Torresdey, J. L. 2013. Toxicity assessment of cerium oxide nanoparticles in cilantro (Coriandrum sativum L.) plants grown in organic soil. J. Agric. Food Chem. 61, 6224-6230.

Mudunkotuwa, I.A., Grassian, V.H. 2010. Citric acid adsorption on $\mathrm{TiO}_{2}$ nanoparticles in aqueous suspensions at acidic and circumneutral $\mathrm{pH}$ : surface coverage, surface speciation, and its impact on nanoparticle-nanoparticle interactions. J. Am. Chem. Soc. 132(42), 14986-14994.

Murguia, I., Tarantino, D., Vannini, C., Bracale, M., Carravieri, S., Soave C. 2004. Arabidopsis thaliana plants overexpressing thylakoidal ascorbate peroxidase show increased resistance to paraquat-induced photooxidative stress and to nitric oxide-induced cell death. Plant J. 38, 940-953.

Niu, Z., Li, Y., 2014. Removal and utilization of capping agents in nanocatalysis. Chem. Mater. 26 (1), 72-83.

Panda, S. K., Choudhury, S. 2005. Chromium stress in plants. Plant Physiol. 2005, 17, 95-102.

Perreault, F., Oukarroum, A., Pirastru, L., Sirois, L., Gerson Matias, W., Popovic, R. 2010. Evaluation of copper oxide nanoparticles toxicity using chlorophyll fluorescence imaging in Lemna gibba. J. Bot. 2010.

Pirmohamed, T., Dowding, J., Singh, S., Wasserman, B., Heckert, E., Karakoti, A.S., King, J.E.S, Seal, S., Self, W.T. 2010. Nanoceria exhibit redox state-dependent catalase mimetic activity. Chem. Commun. 46 (16), 2736-2738.

Porra, R. J. 2002. The chequered history of the development and use of simultaneous equations for the accurate determination of chlorophylls $a$ and $b$. Photosynth. Res. 73, 149-156.

Rabinowitch, E.I., Govindjee. 1965. The role of chlorophyll in photosynthesis. Sci. Am. 213, 7483. 
Rico, C.M., Morales, M.I., Barrios, A.C., McCreary, R., Hong, J., Lee, W.Y., Nunez, J., PeraltaVidea, J.R., Gardea-Torresdey, J.L. 2013a. Effect of cerium oxide nanoparticles on the quality of rice (Oryza sativa L.) grains. J. Agric. Food Chem. 61, 11278-11285.

Rico, C.M., Hong, J., Morales, M.I., Zhao, L., Barrios, A.C., Zhang, J., Peralta-Videa, J.R., Gardea-Torresdey J.L. 2013b. Effect of cerium oxide nanoparticles on rice: A study involving the antioxidant defense system and in vivo fluorescence imaging. Environ. Sci. Technol. 47, 5635-5642.

Rico, C.M., Lee, S.C., Rubenecia, R., Mukherjee, A., Hong, J., Peralta-Videa, J.R., GardeaTorresdey, J.L. 2014. Cerium oxide nanoparticles impact yield and modify nutritional parameters in wheat (Triticum aestivum L.). J. Agric. Food Chem. 62, 9669-9675.

Rico, C.M., Barrios, A.C., Tan, W., Rubenecia, R., Lee, S.C., Varela-Ramirez, A., Peralta-Videa, J.R., Gardea-Torresdey, J.L. 2015. Physiological and biochemical response of soilgrown barley (Hordeum vulgare L.) to cerium oxide nanoparticles. Environ. Sci. Pollut. Res. 22, 10551-10558.

Schwabe, F., Schulin, R., Limbach, L.K., Stark, W., Bürge, D, Nowack, B. 2013. Influence of two types of organic matter on interaction of $\mathrm{CeO}_{2}$ nanoparticles with plants in hydroponic culture. Chemosphere 91, 512-520.

Senden, M.H.M.N., van der Meer, A.J.G.M., Verburg, T.G., Wolterbeek, H.T. 1995. Citric acid in tomato plant roots and its effect on cadmium uptake and distribution. Plant Soil 171, 333-339.

Trujillo-Reyes,J., A.R. Vilchis-Nestor, A.R., Majumdar, S., Peralta-Videa, J.R., GardeaTorresdey, J.L. 2013. Citric acid modifies surface properties of commercial $\mathrm{CeO}_{2}$ nanoparticles reducing their toxicity and cerium uptake in radish (Raphanus sativus) seedlings, J. Hazard. Mater. 263 (2) 677-684.

Wang, Q.; Ma, X.; Zhang, W.; Pei, H.; Chen, Y. 2012. The impact of cerium oxide nanoparticles on tomato (Solanum lycopersicum L.) and its implications on food safety. Metallomics 4, 1105-1112.

Wang, Y., Kinraide, T.B., Wang, P., Hao, X., Zhou, D. 2014. Surface electrical potentials of root cell plasma membranes: implications for ion interactions, rhizotoxicity, and uptake. Int. J. Mol. Sci. 15, 22661-22677.

Zhao, L., Peralta-Videa, J. R., Varela-Ramirez, A., Castillo-Michel, H., Li, C., Zhang, J., Aguilera, R. J., Keller, A., Gardea-Torresdey, J. L. 2012a. Effect of surface coating and organic matter on the uptake of $\mathrm{CeO}_{2} \mathrm{NPs}$ by corn plants grown in soil: insight into the uptake mechanism. J. Hazard. Mater. 225-226, 131- 138.

Zhao, L., Peng, B., Hernandez-Viezcas, J. A., Rico, C., Sun, Y., Peralta-Videa, J. R., Tang, X., Niu, G., Jin, L., Varela, A., Zhang, J., Gardea-Torresdey, J. L. 2012b. Stress response 
and tolerance of Zea mays to $\mathrm{CeO}_{2}$ nanoparticles: Cross talk among $\mathrm{H}_{2} \mathrm{O}_{2}$, heat shock protein, and lipid peroxidation. ACS Nano 6, 9615-9622.

Zhao, L., Sun Y., Hernandez-Viezcas, J.A., Servin, A.D., Hong, J., Niu, G., Peralta-Videa, J.R., Duarte-Gardea, M., Gardea-Torresdey, J.L., 2014. Influence of $\mathrm{CeO}_{2}$ and $\mathrm{ZnO}$ nanoparticles on cucumber physiological markers and bioaccumulation of $\mathrm{Ce}$ and $\mathrm{Zn}$ : A life cycle study. J. Agric. Food Chem. 61, 11945-11951.

Zhao, L., Sun, Y., Hernandez-Viezcas, J.A., Hong, J., Majumdar S., Niu, G., Duarte-Gardea, M., Peralta-Videa, J.R., Gardea-Torresdey, J.L., 2015. Monitoring the environmental effects of $\mathrm{CeO}_{2}$ and $\mathrm{ZnO}$ nanoparticles through the life cycle of corn (Zea mays) plants and in situ $\mu$-XRF mapping of nutrients in kernels. Environ. Sci. Technol. 49, 2921-2928. 


\section{Figure legends}

Figure 1. Ce concentration in roots (A), stems (B), and leaves (C) of tomato plants grown to full maturity (210 days) in soil amended with 0 to $500 \mathrm{mg} / \mathrm{kg}$ of uncoated $\left(\mathrm{nCeO}_{2}\right)$, citric acid coated $\left(\mathrm{CA}+\mathrm{nCeO}_{2}\right) \mathrm{NPs}$, bulk $\mathrm{CeO}_{2}\left(\mathrm{bCeO}_{2}\right)$, cerium acetate $(\mathrm{CeAc})$, and citric acid $(\mathrm{CA})$. Data are means of four replicates \pm SE. Different letters indicate statistically significant differences between concentrations of the same treatment at $(p \leq 0.05) ; n=4$. Citric acid was not included in the figure as it does not contain cerium.

Figure 2. (A) Chlorophyll $a$, (B) chlorophyll $b$, and (C) total chlorophyll contents in leaves of 210 day-old tomato plants grown in soil amended with uncoated $\left(\mathrm{nCeO}_{2}\right)$, citric acid coated $(\mathrm{CA}$ $\left.+\mathrm{nCeO}_{2}\right) \mathrm{NPs}$, bulk $\mathrm{CeO}_{2}\left(\mathrm{bCeO}_{2}\right)$, cerium acetate $(\mathrm{CeAc})$, and citric acid (CA). Data are means of three replicates \pm SE. Different letters indicate statistically significant differences between concentrations from the same treatment at $(p \leq 0.05) ; n=3$.

Figure 3. Antioxidant activity of (A) catalase and (B) ascorbate peroxidase in fresh leaves of 210 day-old tomato plants grown in soil amended with uncoated $\left(\mathrm{nCeO}_{2}\right)$, citric acid coated $(\mathrm{CA}+$ nCeO $\left.\mathrm{C}_{2}\right) \mathrm{NPs}$, bulk $\mathrm{CeO}_{2}\left(\mathrm{bCeO}_{2}\right)$, cerium acetate $(\mathrm{CeAc})$, and citric acid (CA). Data are means of four replicates \pm SE. Different letters indicate statistically significant differences between concentrations from the same treatment at $(p \leq .05) ; n=4$. 


\section{TABLES}

Table 1. Micro- and macro- elements altered in 210 day-old tomato plants exposed to uncoated (nCeO2) and citric acid coated (CA + $\left.\mathrm{nCeO}_{2}\right)$ nanoparticles, cerium acetate $(\mathrm{CeAc})$, and bulk $\mathrm{CeO}_{2}\left(\mathrm{bCeO}_{2}\right)$. Data are average $\pm \mathrm{SE}$ of four replicates, except control (Millipore water) that had 16 replicates. Comparisons were made with respect to the controls and symbols + and - stand for percent of increase and decrease in nutrient concentration.

\begin{tabular}{|c|c|c|c|c|}
\hline Ora & Element & $\begin{array}{c}\text { Treatment } \\
\text { (mg/kg soil) }\end{array}$ & $\begin{array}{c}\text { Concentration } \\
\text { (mg/kg d wt tissue) } \\
\end{array}$ & $\%$ \\
\hline Roots & $\begin{array}{c}\mathrm{Fe} \\
\mathrm{B}\end{array}$ & $\begin{array}{l}\text { Control } \\
\text { Coated NP } 62.5 \\
\text { CeAc } 62.5 \\
\text { Control } \\
\text { CeAc } 62.5 \\
\text { Control } \\
\text { CeAc } 125 \\
\end{array}$ & $\begin{array}{c}1732.3 \pm 171.6 \\
4760.0 \pm 1122.2 \\
5130.4 \pm 820.0 \\
1268.1 \pm 104.2 \\
3470.1 \pm 488.9 \\
30.5 \pm 2.7 \\
55.0 \pm 3.2 \\
\end{array}$ & $\begin{array}{c}100 \\
174.8+ \\
196.2+ \\
100 \\
173.6+ \\
100 \\
80.5+ \\
\end{array}$ \\
\hline Stems & $\begin{array}{c}\mathbf{P} \\
\mathbf{Z n}\end{array}$ & $\begin{array}{l}\text { Control } \\
\mathrm{CeAc} 250 \\
\mathrm{CeAc} 500 \\
\mathrm{Control} \\
\mathrm{bCeO}_{2} 125 \\
\mathrm{Control} \\
\mathrm{bCeO}_{2} 62.5 \\
\end{array}$ & $\begin{array}{c}10473.5 \pm 540.3 \\
19295.1 \pm 2587.2 \\
19501.0 \pm 255.82 \\
39993.1 \pm 255.8 \\
7853.1 \pm 594.8 \\
71.9 \pm 7.7 \\
181.6 \pm 17.5 \\
\end{array}$ & $\begin{array}{c}100 \\
84.2+ \\
86.2+ \\
100 \\
80.4- \\
100 \\
152.5+ \\
\end{array}$ \\
\hline Leaves & Al & $\begin{array}{l}\text { Control } \\
\text { Coated NP 250 }\end{array}$ & $\begin{array}{c}189.2 \pm 13.4 \\
530.1 \pm 131.8\end{array}$ & $\begin{array}{r}100 \\
180.2+\end{array}$ \\
\hline
\end{tabular}


Table 2. Total production, percentage of mature fruits at 151 and 210 days, and fruits with blossom end rot at 210 days in tomato plants grown in soil amended with 0 (control) to 500 $\mathrm{mg} / \mathrm{kg}$ of uncoated $\left(\mathrm{nCeO}_{2}\right)$, citric acid coated $\left(\mathrm{CA}+\mathrm{nCeO}_{2}\right) \mathrm{NPs}$, bulk $\mathrm{CeO}_{2}\left(\mathrm{bCeO}_{2}\right)$, cerium acetate $(\mathrm{CeAc})$, and citric acid (CA). The control treatment was watered with Millipore water. DAG stands for days after germination.*Total number of tomatoes for 4 replicates.

\begin{tabular}{|c|c|c|c|c|c|}
\hline Treatment & $\mathrm{mg} / \mathrm{kg}$ & $\begin{array}{c}\text { No. } \\
\text { tomatoes* }\end{array}$ & $\begin{array}{c}\text { Mature } \\
\text { (139-151 DAG) } \\
\% \\
\end{array}$ & $\begin{array}{c}\text { Never ripened } \\
\text { (210 DAG) } \\
\% \\
\end{array}$ & $\begin{array}{c}\text { Blossom end rot } \\
\% \\
\end{array}$ \\
\hline \multirow{5}{*}{$\mathrm{nCeO}_{2}$} & 0 & 6 & 83.3 & 16.7 & 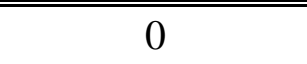 \\
\hline & 62.5 & 18 & 38.9 & 27.8 & 0 \\
\hline & 125 & 6 & 50 & 16.7 & 0 \\
\hline & 250 & 9 & 66.7 & 11.1 & 0 \\
\hline & 500 & 5 & 0 & 40 & 0 \\
\hline \multirow{5}{*}{$\begin{array}{c}\mathrm{CA}+ \\
\mathrm{nCeO}_{2}\end{array}$} & 0 & 7 & "57.14 & 14.3 & 14.3 \\
\hline & 62.5 & 8 & 37.5 & 37.5 & 12.5 \\
\hline & 125 & 5 & 40 & 0 & 0 \\
\hline & 250 & 8 & 25 & 0 & 25 \\
\hline & 500 & 6 & 0 & 0 & 16.7 \\
\hline \multirow{5}{*}{$\mathrm{bCeO}_{2}$} & 0 & 4 & 75 & 25 & 0 \\
\hline & 62.5 & 3 & 0 & 100 & 0 \\
\hline & 125 & 0 & 0 & 0 & 0 \\
\hline & 250 & 4 & 50 & 0 & 0 \\
\hline & 500 & 5 & 40 & 20 & 0 \\
\hline \multirow{5}{*}{$\mathrm{CeAc}$} & 0 & $\overline{5}$ & 100 & 0 & 0 \\
\hline & 62.5 & 4 & 25 & 0 & 0 \\
\hline & 125 & 5 & 0 & 0 & 0 \\
\hline & 250 & 3 & 0 & 33.3 & 0 \\
\hline & 500 & 6 & 33.3 & 16.7 & 16.7 \\
\hline \multirow{5}{*}{$\mathrm{CA}$} & 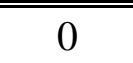 & 8 & 62.5 & 12.5 & 0 \\
\hline & 62.5 & 6 & 16.7 & 0 & 0 \\
\hline & 125 & 1 & 0 & 100 & 100 \\
\hline & 250 & 12 & 50 & 25 & 0 \\
\hline & 500 & 1 & 0 & 0 & 0 \\
\hline
\end{tabular}




$$
\begin{aligned}
& 28 \\
& 28 \\
& 29
\end{aligned}
$$$$
30
$$$$
31
$$

Table 3. Shoot length of 15,60 , and 210 day-old tomato plants grown in soil amended with uncoated $\left(\mathrm{nCeO}_{2}\right)$, citric acid coated $\left(\mathrm{CA}+\mathrm{nCeO}_{2}\right) \mathrm{NPs}$, bulk $\mathrm{CeO}_{2}\left(\mathrm{bCeO}_{2}\right)$, cerium acetate (CeAc), and citric acid (CA). Data are means of four replicates \pm SE. Different letters indicate

\begin{tabular}{|c|c|c|c|c|c|c|}
\hline & & Control & 62.5 & 125 & 250 & 500 \\
\hline \multirow{3}{*}{$\mathrm{nCeO} 2$} & 15 & $17.33 \pm 0.30$ & $15.94 \pm 0.07$ & $14.73 \pm 1.00$ & $16.33 \pm 0.19$ & $16.96 \pm 0.74$ \\
\hline & 60 & $49.65 \pm 0.21 \mathrm{a}$ & $40.49 \pm 0.93 b$ & $39.55 \pm 0.84 b$ & $44.11 \pm 1.94 \mathrm{ab}$ & $46.10 \pm 0.90 \mathrm{ab}$ \\
\hline & 210 & $146.31 \pm 0.27 \mathrm{~b}$ & $135.99 \pm 0.03 b$ & $112.21 \pm 0.15 c$ & $142.21 \pm 1.30 \mathrm{~b}$ & $162.20 \pm 1.80 \mathrm{a}$ \\
\hline \multirow{3}{*}{$\mathrm{CA}+\mathrm{nCeO} 2$} & 15 & $14.38 \pm 0.22$ & $14.57 \pm 0.16$ & $1014.66 \pm 0.46$ & $16.13 \pm 0.48$ & $14.76 \pm 0.04$ \\
\hline & 60 & $47.22 \pm 1.02 \mathrm{a}$ & $41.66 \pm 1.51 \mathrm{~b}$ & $43.25 \pm 1.05 \mathrm{ab}$ & $44.53 \pm 0.67 \mathrm{ab}$ & $43.26 \pm 0.43 \mathrm{ab}$ \\
\hline & 210 & $145.64 \pm 1.12 \mathrm{c}$ & $136.06 \pm 2.41 \mathrm{~d}$ & $130.09 \pm 1.07 \mathrm{~d}$ & $158.61 \pm 1.85 \mathrm{~b}$ & $168.49 \pm 1.73 \mathrm{a}$ \\
\hline \multirow{3}{*}{$\mathrm{bCeO} 2$} & 15 & $13.26 \pm 0.20$ & $13.54 \pm 0.87$ & $14.48 \pm 1.15$ & $15.91 \pm 0.26$ & $1616.46 \pm 0.79$ \\
\hline & 60 & $49.76 \pm 0.21 \mathrm{a}$ & $44.54 \pm 0.75 b$ & $39.68 \pm 0.72 b$ & $31.62 \pm 0.48 c$ & $30.57 \pm 0.36 c$ \\
\hline & 210 & $149.19 \pm 1.47 \mathrm{a}$ & $89.48 \pm 0.55 \mathrm{~b}$ & $83.11 \pm 0.02 b c$ & $81.55 \pm 0.20 b c$ & $78.13 \pm 0.05 c$ \\
\hline \multirow{3}{*}{$\mathrm{CeAc}$} & 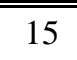 & $\begin{array}{l}15.03 \pm 0.44 \\
\end{array}$ & $15.19 \pm 0.18$ & $1015.11 \pm 0.04$ & $\begin{array}{l}16.37 \pm 0.22 \\
\end{array}$ & $=15.04 \pm 0.85$ \\
\hline & 60 & $48.68 \pm 0.47$ & $46.91 \pm 0.71$ & $45.05 \pm 1.49$ & $46.33 \pm 1.12$ & $47.75 \pm 0.68$ \\
\hline & 210 & $144.38 \pm 0.25 \mathrm{a}$ & $140.31 \pm 0.02 \mathrm{ab}$ & $135.10 \pm 1.16 \mathrm{bc}$ & $127.00 \pm 0.49 c$ & $106.31 \pm 1.53 \mathrm{~d}$ \\
\hline \multirow{3}{*}{$\mathrm{CA}$} & 15 & $\begin{array}{l}15.27 \pm 0.29 \\
\end{array}$ & $15.43 \pm 0.09$ & $16.28 \pm 0.43$ & $1616.39 \pm 0.81$ & $1616.03 \pm 0.37$ \\
\hline & 60 & $49.33 \pm 1.05 b c$ & $40.22 \pm 0.82 c$ & $45.28 \pm 0.73 \mathrm{ab}$ & $54.55 \pm 0.30 \mathrm{a}$ & $52.88 \pm 0.32 \mathrm{a}$ \\
\hline & 210 & $144.38 \pm 0.21$ & $148.65 \pm 1.47$ & $144.74 \pm 1.65$ & $156.04 \pm 0.77$ & $156.81 \pm 1.23$ \\
\hline
\end{tabular}
statistically significant differences between concentrations at $(p \leq 0.05) ; n=4$. 


\section{FIGURES}

A

$\square$ Control $\square 62.5 \quad \square 125 \quad \square 250 \quad \square 500$

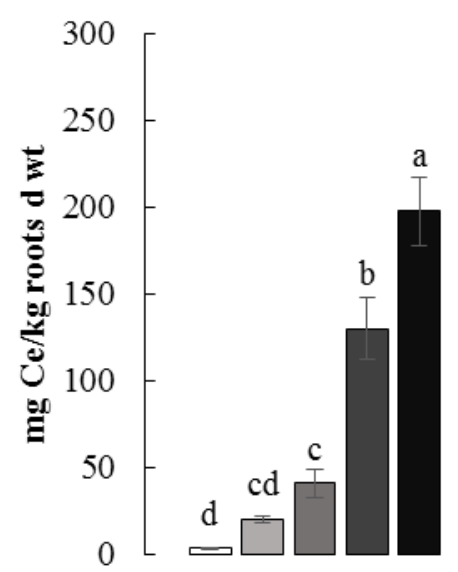

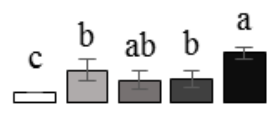

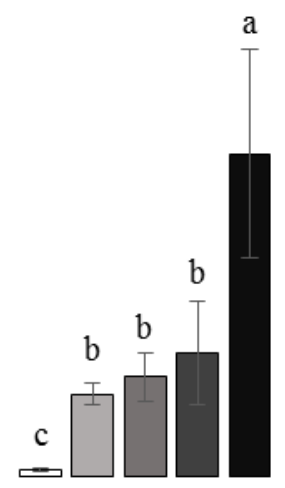

B
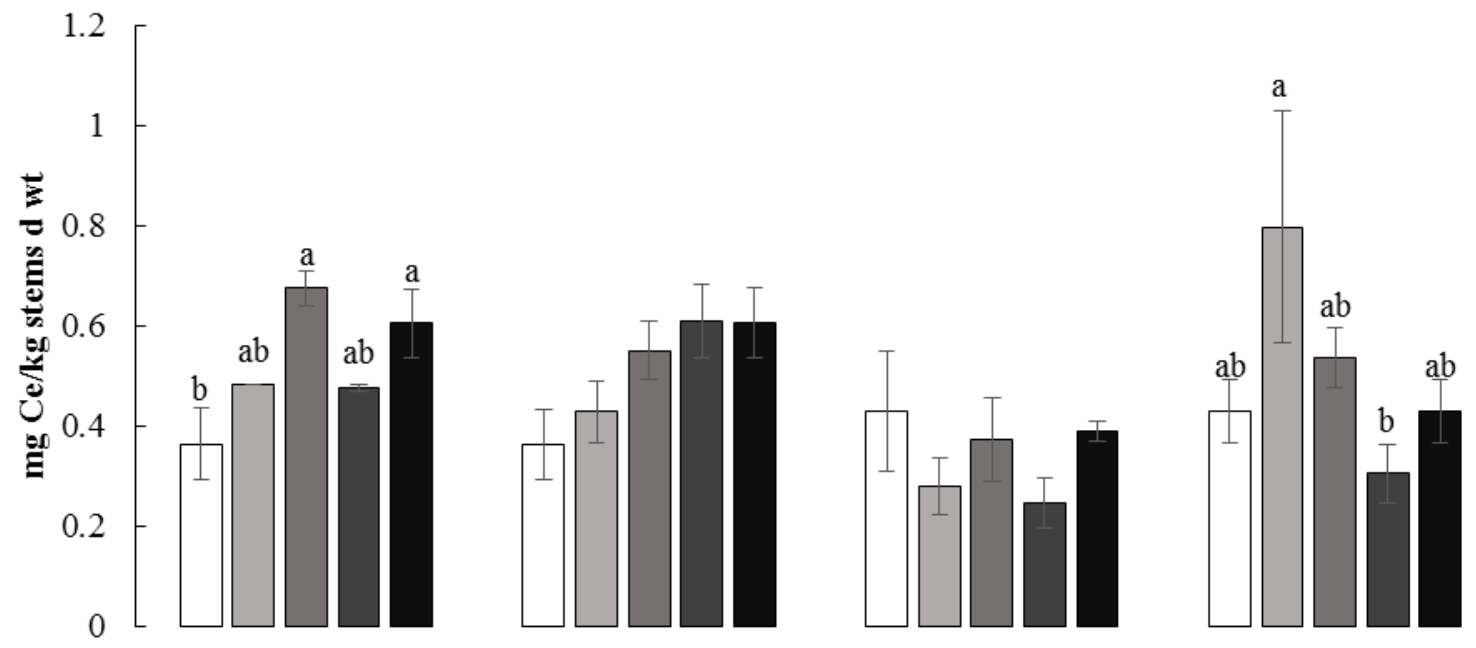

C
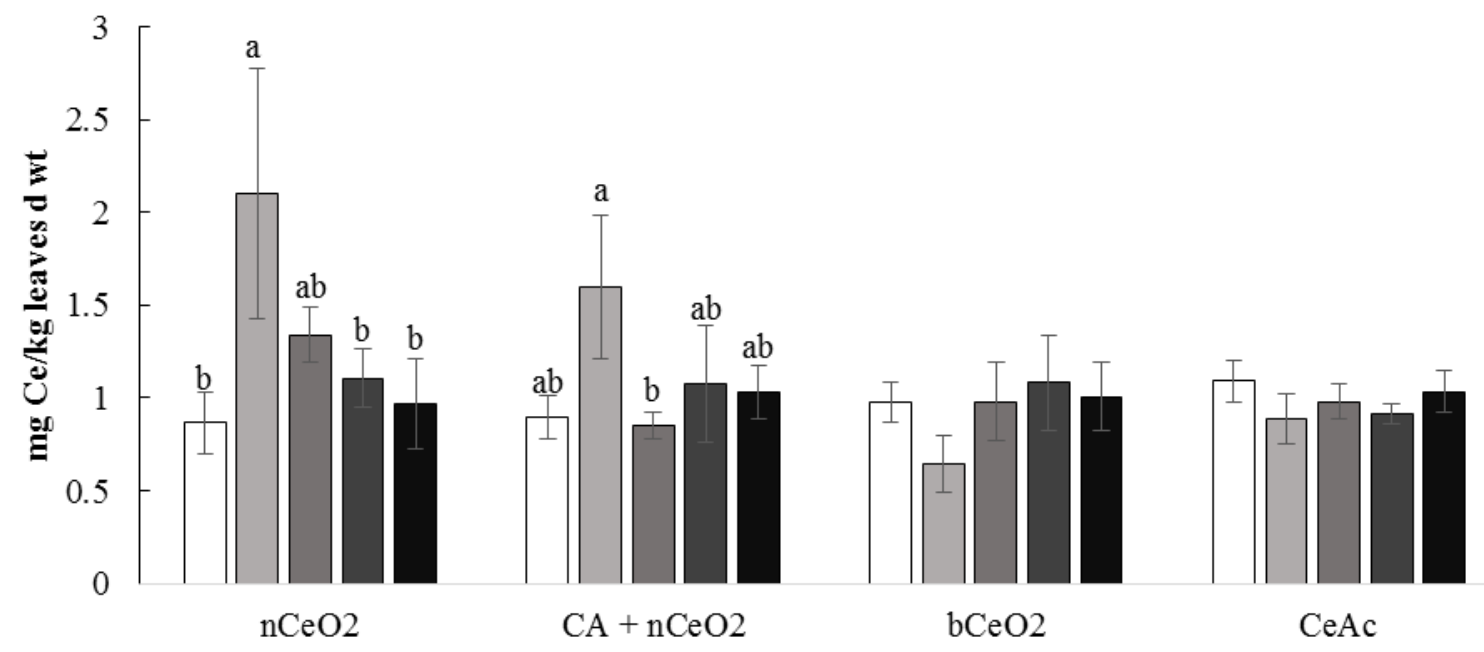

Treatment

Figure 1. 

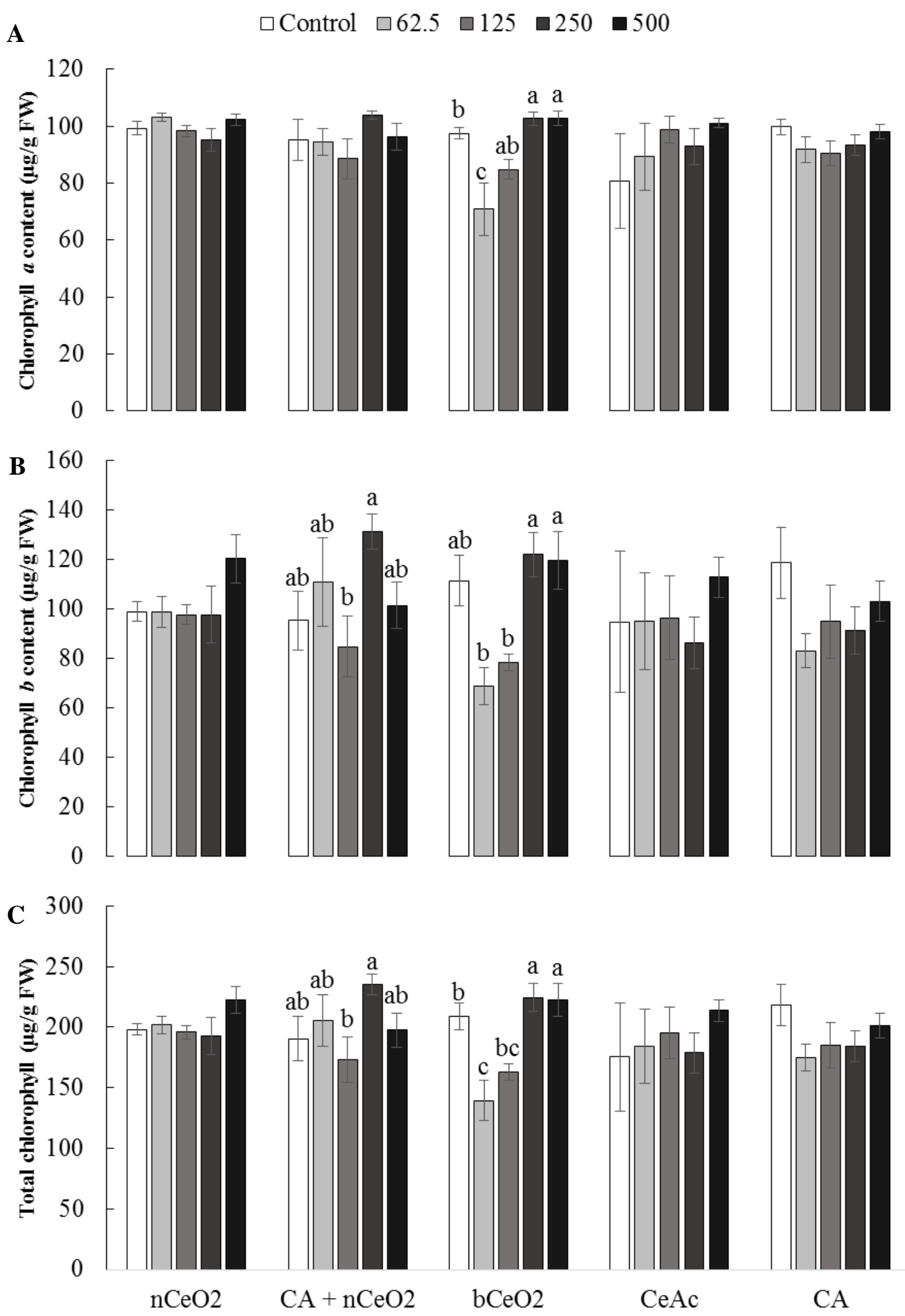

Treatment

Figure 2. 
A CAT

$\square$ Control $\square 62.5 \quad \square 125 \quad \square 250 \quad \square 500$
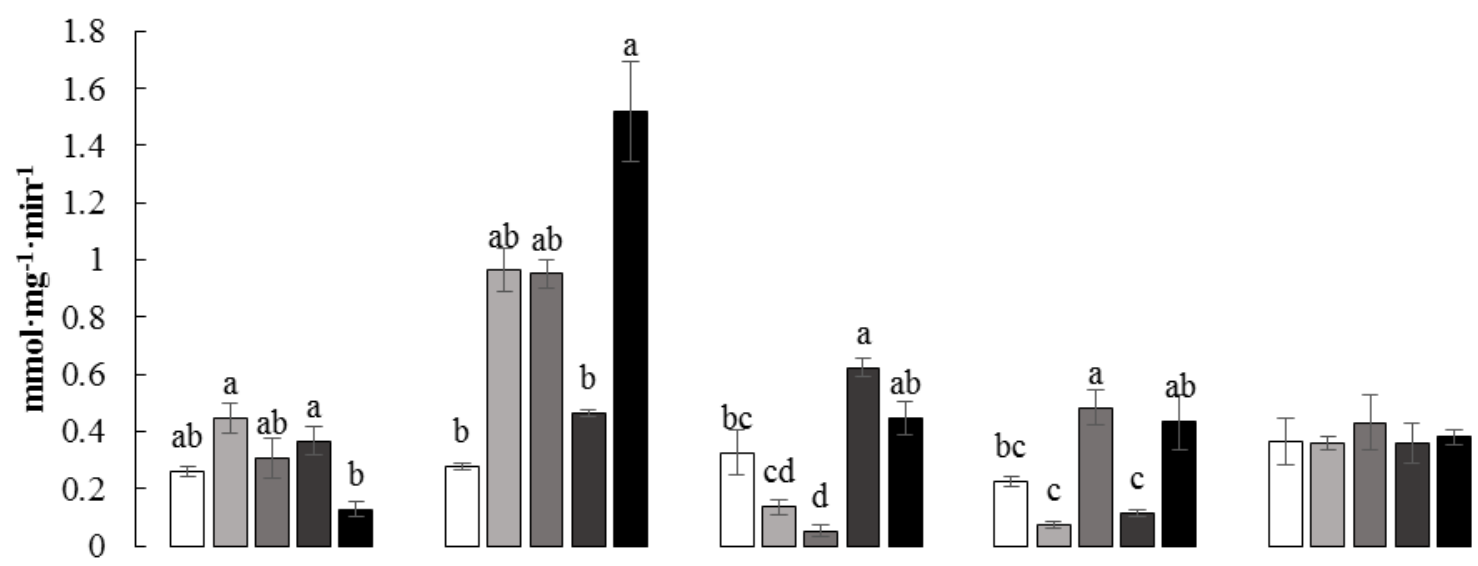

B APOX
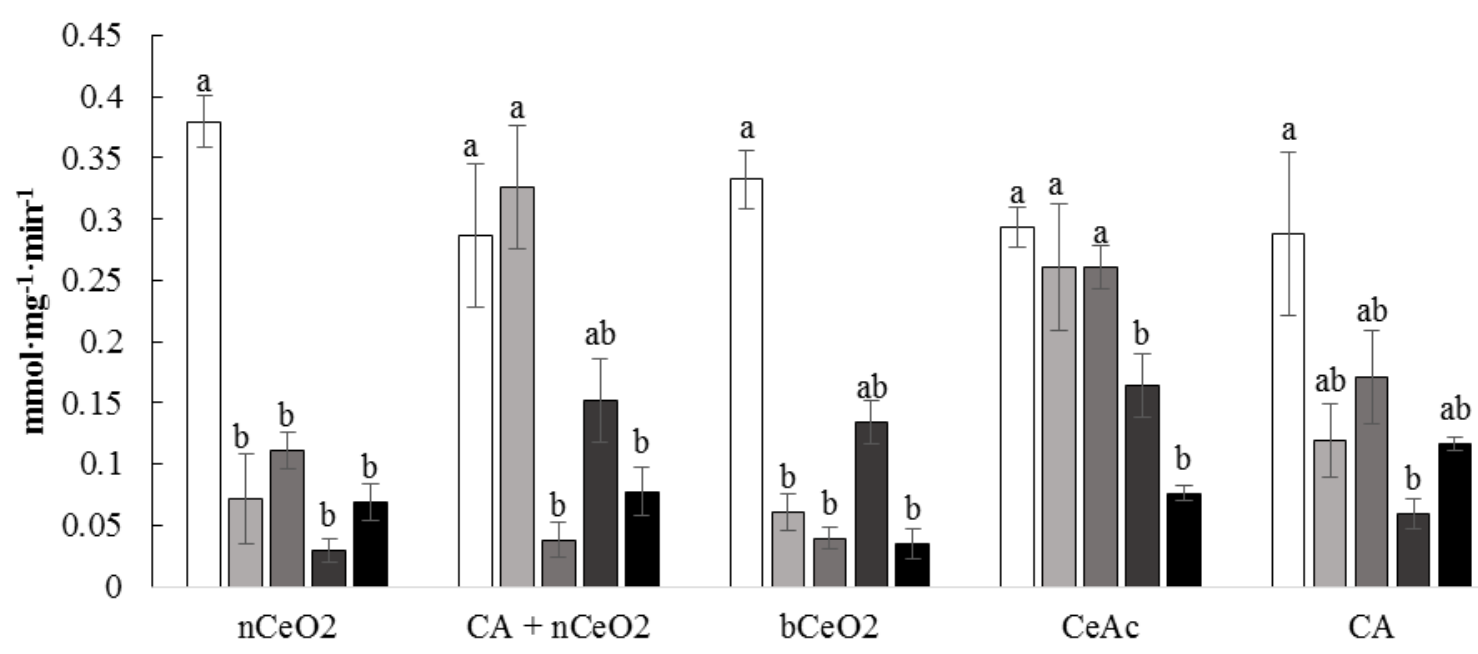

Treatment

Figure 3. 
bare $\mathrm{CeO}_{2} \mathrm{NP}$ Citric acid coated $\mathrm{CeO}_{2}$ NP Bulk $\mathrm{CeO}_{2}$ Cerium acetate Citric acid

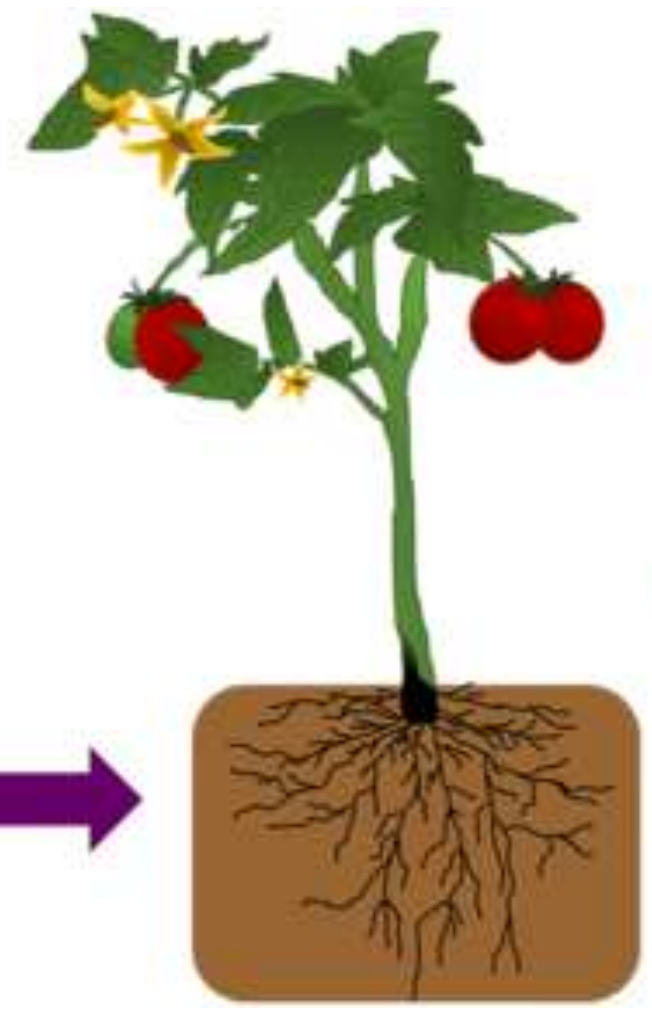

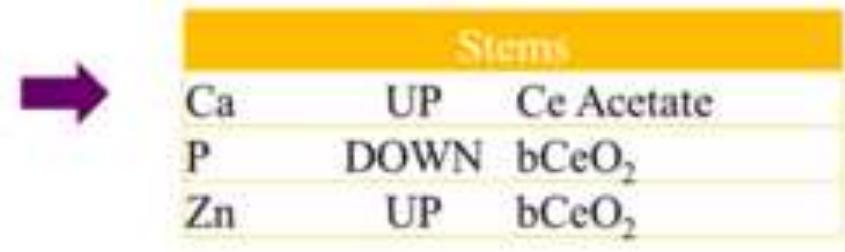

$\Rightarrow \begin{array}{lll}\mathrm{Fe} & \text { UP } & \text { Ce Acetate } \\ \mathrm{B} & \text { UP } & \text { CeAcetate }\end{array}$

\begin{tabular}{lll}
\hline 500 mg/kg & CAI & APOX \\
\hline Bare NP & DOWN \\
Coated NP & UP & DOWN \\
bCeO & & DOWN \\
Ce Acetate & DOWN
\end{tabular}

